\title{
THE RADIOCARBON DATA BASE AT RUDJER BOŠKOVIĆ INSTITUTE RADIOCARBON LABORATORY
}

\author{
BOGOMIL OBELIĆ
}

\author{
Rudjer Bošković Institute, P O B 1016, Zagreb, Yugoslavia
}

\begin{abstract}
A multidisciplinary radiocarbon data base system written in dBASE III PLUS which follows the recommendations of the International Database Cornmission and specific requirements of our laboratory is described. The system updates, stores and maintains records and retrieves data according to specific key-words.
\end{abstract}

\section{INTRODUCTION}

The need for computer processing and data entry into a data base was realized very soon after starting the Rudjer Bošković Institute Radiocarbon Laboratory in the early 1970s. These systems were established on a UNIVAC 1110 computer located at the University Computing Center, and later transferred to an HP-1000 located at the Institute. Our data base contains basic data on samples and results measured at our laboratory, including comprehensive karst studies phenomena, in which several hundreds of isotopic data obtained on calcite deposits, water and various biological samples have been analyzed (Srdoč et al, 1980, 1985, 1986). We can also prepare date lists for publication in RADIOCARBON from our data base.

The recent aquisition of an IBM-compatible PC, sponsored by the IAEA in 1987, enabled us to design a sophisticated multidisciplinary data base, which is exclusive to our laboratory. Creation and updating of data stored at Rudjer Bošković Radiocarbon Data Base include entering all relevant data on submitted samples, sample pretreatment and preparation and measurement in the proportional counter. Data retrieval from samples of various series, archaeologic or geologic periods, age intervals, regions, etc, is possible by selecting desired key-words. Records can be displayed on the screen, printed out for mailing or transferred to another database form for exchange with other laboratories.

The computer system consists of an EMD PC-1021 (IBM AT-compatible) with Hercules monochrome card, 640 kbytes of RAM and $20 \mathrm{MBy}$ hard disk. A backup copy of the contents of the hard disk can be made on a magnetic tape, and separate files or entire directories are copied onto floppy diskettes. We use the DOS operating system, version 3.21, Microsoft Fortran 77 and dBASE III PLUS, version 1.1.

\section{DATABASE FILES}

Data are entered into a menu-accessed dBASE III PLUS program and stored on four database files (DBF) and corresponding database memo files (DBT) for comments which occupy an unlimited number of characters, as follows:

C14S.DBF - Data on submitted samples and final results of measurement

C14P.DBF - Data on sample pretreatment

C14M.DBF - Data on measurement in the proportional counter 
C14B.DBF - Data on inactive and active standards

Data bases 1, 2 and 3 are linked together with our lab code designation, Z. C14S.DBF is the only database file important for users and for exchanging data. It consists of 39 fields (296 bytes) which follow those recommended by the International Database Commission (Kra, 1986) (Fig 1). Each sample is identified by a separate record. Descriptions in each record are entered as characters, but a relatively large part of the infor-

\begin{tabular}{|c|c|c|c|c|}
\hline Field & Field name & Type & Width & Description \\
\hline 1 & LAB-NO & Numeric & 5 & Laboratory number $(\mathrm{Z}-\ldots)$ \\
\hline 2 & LAB-CODE & Character & 1 & Sample material code (fig. 2) \\
\hline 3 & SERIES & Character & 12 & Series \\
\hline 4 & DISCIPLINE & Character & 5 & Scientific discipline (fig. 4) \\
\hline 5 & SAMPLE-MAT & Character & 15 & Sample material description \\
\hline 6 & SITE-TYPE & Character & 45 & Description of site \\
\hline 7 & SAMPLE-NO & Numeric & 4 & Sample number within a series \\
\hline 8 & SITENAME & Character & 15 & Name of the narest site \\
\hline 9 & STATE & Character & 10 & Federal state or province \\
\hline 10 & COUNTRY & Character & 10 & Country \\
\hline 11 & LAT-DEG & Numeric & 2 & Geographic latitude (DD $\left.{ }^{\circ} \mathrm{MM}^{\prime} \mathrm{SS}^{\prime \prime}\right)$ \\
\hline 12 & LAT-MIN & Numeric & 2 & 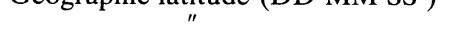 \\
\hline 13 & LAT-SEC & Numeric & 2 & $"$ \\
\hline 14 & GEOG-LAT & Character & 1 & $" \quad(\mathrm{~N}, \mathrm{~S})$ \\
\hline 15 & LONG-DEG & Numeric & 2 & Geographic longitude (DD ${ }^{\circ} \mathrm{MM}^{\prime} \mathrm{SS}^{\prime \prime}$ ) \\
\hline 16 & LONG-MIN & Numeric & 2 & gento \\
\hline 17 & LONG-SEC & Numeric & 2 & $"$ \\
\hline 18 & GEOG-LONG & Character & 1 & $" \quad(\mathrm{E}, \mathrm{W})$ \\
\hline 19 & HEIGHT-ASL & Numeric & 5 & Height above sea level (m) \\
\hline 20 & STRAT & Numeric & 5 & Stratigraphic data $(\mathrm{cm}, \mathrm{m})$ \\
\hline 21 & COLL-BY & Character & 15 & Collector's name \\
\hline 22 & COLL-DATE & Date & 8 & Date of collection \\
\hline 23 & COLL-INST & Character & 10 & Code of collector's institution \\
\hline 24 & SUBM-BY & Character & 15 & Submitter's name \\
\hline 25 & SUBM-DATE & Date & 8 & Date of submission \\
\hline 26 & SUBM-INST & Character & 10 & code of submitter's institution \\
\hline 27 & CULT-PD & Character & 3 & Culture - archaeol or geol period code \\
\hline 28 & $\mathrm{EXP}-\mathrm{AGE}$ & Numeric & 5 & Expected age (years BP) \\
\hline 29 & $\mathrm{C} 13$ & Numeric & 6,2 & $\delta^{13} \mathrm{C}$ value \\
\hline 30 & $\mathrm{C}-\mathrm{C} 13$ & Numeric & 4,2 & $\delta^{13} \mathrm{C}$ error \\
\hline 31 & INIT-ACT & Numeric & 5 & Initial activity (in \%) \\
\hline 32 & MEASURED & Numeric & 3 & Number of measurements \\
\hline 33 & PM-KON & Numeric & 6,2 & Result in percent modern \\
\hline 34 & SPM-KON & Numeric & 4,2 & Error of percent modern \\
\hline 35 & AGE-KON & Numeric & 6 & Age (BP) \\
\hline 36 & AGES-KON & Numeric & 4 & Age error (BP) \\
\hline 37 & RANGE-KON & Character & 15 & Calibrated range (AD, BC) \\
\hline 38 & RADIOCARB & Numeric & 2 & $\begin{array}{l}\text { Rudjer Bošković Institute } \\
\text { RADIOCARBON date list No. }\end{array}$ \\
\hline 39 & SUB-COMM & Memo & 10 & $\begin{array}{l}\text { Collector's and/or submitter's } \\
\text { comment (unlimited length) }\end{array}$ \\
\hline
\end{tabular}

Fig 1. Structure of database C14S.DBF 
mation is in numeric form. Numeric data entered as characters can occupy a different position in the required character field, enabling correct retrieval and sorting of records. Although the data base proposed by the International Database Commission consists of character fields only, the transformation of our data base is easily possible by using the dBASE III PLUS software program.

C14P.DBF consists in data on pretreatment and preparation of samples for measurement in the proportional counter. All samples are first burned to $\mathrm{CO}_{2}$ (carbonate samples are converted to $\mathrm{CO}_{2}$ by reaction with acid). After purification, $\mathrm{CO}_{2}$ is converted to methane which we use as the counting gas. Creating a separate record for each preparation allows for the possibility of different or repeated preparations. With this database file, we can follow the "history" of various preparation devices to find possible sources of contamination (memory effect).

C14M.DBF consists in data on measurement in the proportional counter, as well as some meteorological data. A separate record is created for each measurement. After calculation, results of every measurement are also stored in this database file.

C14B.DBF consists in records of inactive and active standards, as measured in consecutive periods. The program automatically retrieves those values of standards which correspond to each measurement.

\section{CALCULATION}

To use the data bases, as well as to calculate results of measurements, a desired operation is chosen from the main menu (Fig 2). Operation " $A$ " activates a software chain of data including updating (C14S.DBF), sample preparation (C14P.DBF) and measurement (C14M.DBF). Each measurement in the proportional counter takes ca $24 \mathrm{hr}$ and the count rate, divided into 20 min intervals, is printed out. After entering the main data on the measurement into File C14M.DBF, the program calls a FORTRAN

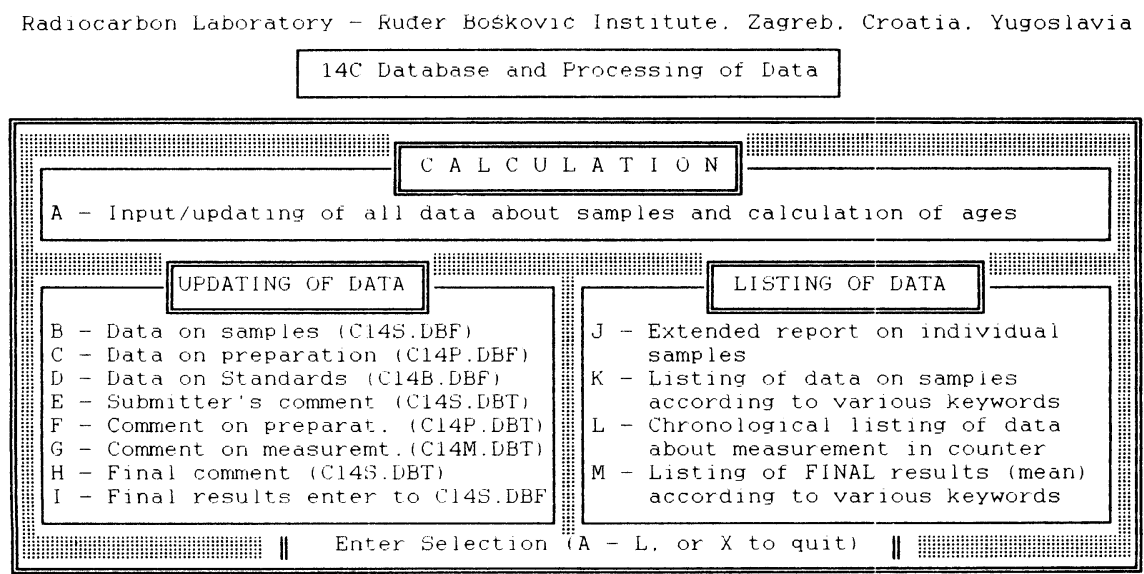


program for data processing, statistical processing and calculating of results. This is a revised version of the program described by Obelić \& Planinić (1977). Results are again stored in C14M.DBF and printed out for checkup. After the last measurement of a sample, a final report can be created and the averaged values of results can be stored in C14S.DBF. All finalized results are calibrated according to a simplified version of the program designed at the University of Washington (Stuiver \& Reimer, 1986). Statistical processing of data is written in FORTRAN, while all other steps are written in dBASE III PLUS. $\delta^{13} \mathrm{C}$ correction can be made for each sample individually. However, if $\delta^{13} \mathrm{C}$ data do not exist, age correction due to isotopic fractionation is made for various sample materials according to suggestions of Stuiver and Polach (1977).

\section{DATA RETRIEVAL}

One of the main tasks of a database program is retrieval of records of particular interest. By calling the dBASE III PLUS routine, SEEK, searching for single records indexed on laboratory numbers takes only several seconds. By selecting the appropriate operation at the main menu, we can add new or update existing records. We can retrieve particular records or groups of records by entering specific key-words or key-codes into the command, FILTER, which displays records of a database file that meet a specific condition, as shown in Figure 3. Key-words can be related to

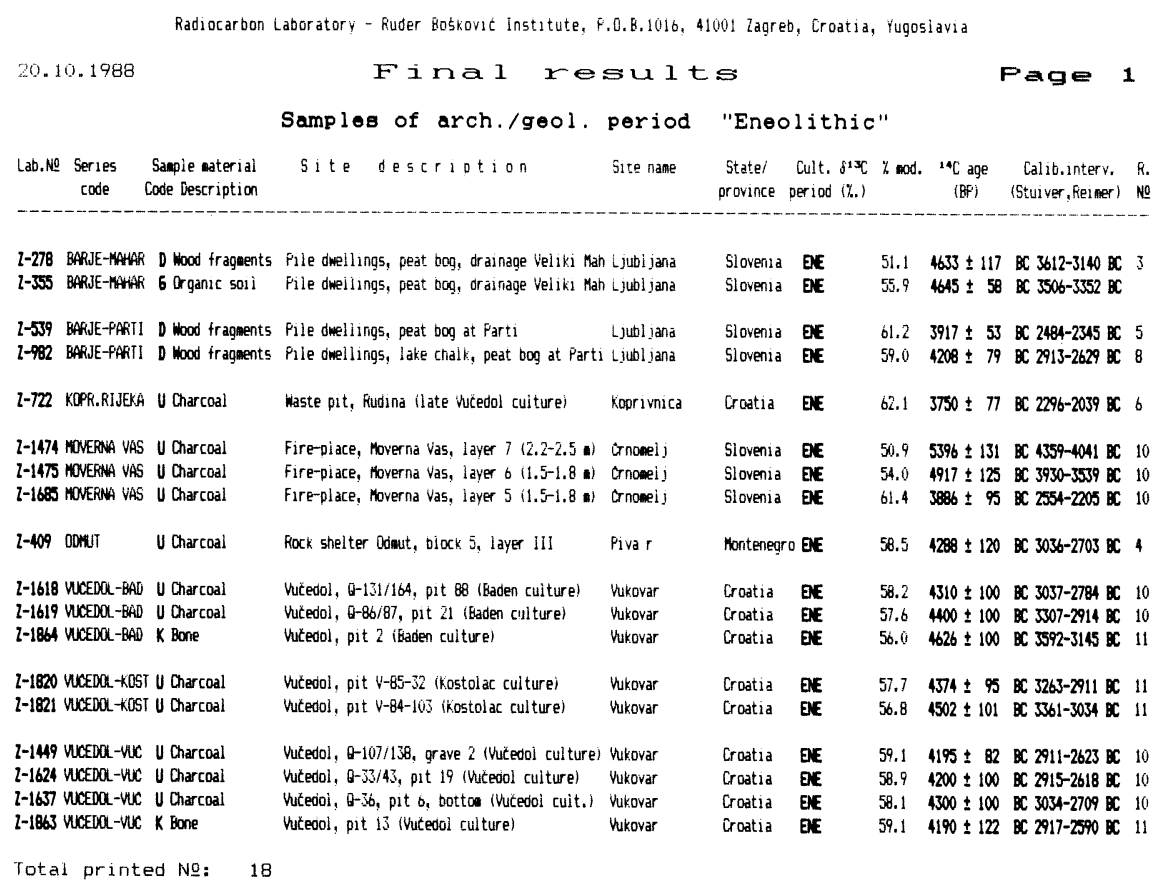

Fig 3. Listing of final results for some samples of culture period denoted by ENE (Eneolithic). Last column (R No.) denotes number of Rudjer Bošković Institute RADIOCARBON date list where data about the sample were published. 
specific research fields, sample material codes, age interval, countries and regions, collectors and submitters and serial codes which allows for easy retrieval of all relevant data (Fig 4).

Disciplines (fields)

$$
\begin{aligned}
& \text { ARCH - Archaeology } \\
& \text { BIOL - Biology } \\
& \text { ENV - Environmental sciences } \\
& \text { GEOL - Geology } \\
& \text { HYDRO - Hydrology } \\
& \text { STAND - Samples of standard }
\end{aligned}
$$

Sample material
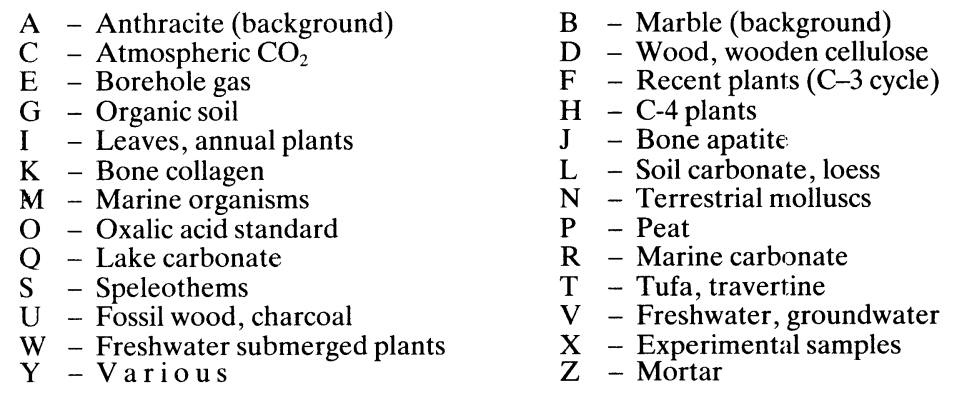

Archaeological and geological periods

$\begin{array}{ll}\text { Archaeology } & \text { Geology } \\ \text { PALaeolithic } & \text { PLEistocene } \\ \text { MESolithic } & \text { HOLocene } \\ \text { NEOlithic } & \\ \text { ENEolithic } & \\ \text { BROnze age } & \\ \text { IROn age } & \\ \text { EAStern cultures } & \\ \text { ANTique period } & \\ \text { MIDdle ages } & \\ \text { NEW age } & \\ \text { MODern sample } & \end{array}$

Fig 4. List of key-words used in the data base

\section{COMMENTS AND CONCLUSION}

We tested our data base on a set of data that contained more than 2500 records. We are convinced that the transformation to other data bases should not cause any problems, and requires only a relatively simple software, because dBASE III PLUS facilitates copying other database structures of the same type or similar types to SDF (System Data Format ASCII), DIF (VisiCalc), SYLK (Multiplan), WKS (Lotus 1-2-3) or others.

Probably the most difficult problem would come from using key-word or key-code systems that are developed independently by other laboratories. Key-words that denote sample materials, regions (countries), 
archaeologic or geologic periods and other data relevant to each sample have to be standardized. This is of particular importance for archaeologic and/or geologic periods. Some laboratories use designations for more extended periods (eg, Holocene in geology or Paleolithic in archaeology), while others denote more specific periods (Boreal, Atlanticum, ...or Gravettian, Aurignacian, etc). Different names may be used for the same periods (Eneolithic vs Chalcolithic, Younger Holocene vs Lower Holocene). The International Radiocarbon Database Commission should design a list of key-words acceptable to all laboratories and users.

More than 2500 samples related to archaeology, geology and other fields have been measured at our laboratory since 1970 . By creating a data base, we hope to simplify reporting radiocarbon results to our submitters, to prepare date lists for publication in RADIOCARBON, and to transmit radiocarbon results on floppy diskettes to the proposed International Radiocarbon Data Base (IRDB). Our main problem for simultaneous use of the data base for reporting data to submitters and later publication in RADIOCARBON or in the international exchange, is language. Specific data about samples and especially comments cannot be written in our language and English at the same time.

\section{REFERENCES}

Kra, R, 1986, Report on the ${ }^{14} \mathrm{C}$ Database Workshop, in Stuiver, M and Kra, R S, eds, Internatl ${ }^{14} \mathrm{C}$ conf, 12th, Proc: Radiocarbon, v 28, no.2A, p 800-802

Obelić, B and Planinić, J, 1977, Computer processing of radiocarbon and tritium data, in Internatl conf on low-radioactivity measurements and applications, High Tatras, Proc: Slovenske Pedagogicke Nakladatel'stvo, Bratislava, p 117-122.

Srdoč, D, Obelić, B, Horvatinčić, N and Sliepčević, A, 1980, Radiocarbon dating of calcareous tufa: How reliable data can we expect?, in Stuiver, M and Kra, R S, eds, Internatl ${ }^{14} \mathrm{C}$ conf, 10th, Proc: Radiocarbon, v 22, no.3, p 858-862.

Srdoč, D, Horvatinčić, N, Obelić, B, Krajcar Bronić, I and Sliepčević, A, 1985, Calcite deposition processes in karst waters with special emphasis on the Plitvice Lakes, Yugoslavia: Carsus Iugoslaviae, v 11/4-6, p 101-204.

Srdoč, D, Obelić, B, Horvatinčić, N, Krajcar Bronić, I, Marčenko, E, Merkt, J, Wong, H K and Sliepčević, A, 1986, Radiocarbon dating of lake sediment from two karst lakes in Yugoslavia, in Stuiver, $\mathrm{M}$ and $\mathrm{Kra}, \mathrm{R} \mathrm{S}$, eds, Internatl ${ }^{14} \mathrm{C}$ conf, $12 \mathrm{th}$, Proc: Radiocarbon, v 28, no.2A, p 495-509.

Stuiver, M and Polach, H, 1977, Discussion - Reporting of ${ }^{14} \mathrm{C}$ data: Radiocarbon, v 19, no.3, p 355-363.

Stuiver, $\mathrm{M}$ and Reimer, PJ, 1986, Computer program for calibration of ${ }^{14} \mathrm{C}$ data, in Stuiver, $\mathrm{M}$ and Kra, RS, eds, Internatl ${ }^{14} \mathrm{C}$ conf, 12th, Proc: Radiocarbon, v 28, no.2A, p 1022-1030. 